\title{
AS SUBJETIVIDADES DO PACIENTE ONCOLÓGICO EM UM HOSPITAL DE ENSINO: SOB A PERSPECTIVA DO ASSISTENTE SOCIAL
}

\author{
THE SUBJECTIVITIES OF THE ONCOLOGICAL PATIENT IN A TEACHING HOSPITAL: \\ UNDER THE SOCIAL ASSISTANT'S PERSPECTIVE
}

\section{LAS SUBJETIVIDADES DEL PACIENTE ONCOLÓGICO EN UN HOSPITAL DOCENTE: DESDE LA PERSPECTIVA DEL ASISTENTE SOCIAL}

Lena Lansttai Bevilaqua Menezes ${ }^{1}$ Eli Fernanda Brandão Lopes ${ }^{2}$

\section{Resumo}

O câncer é apontado como a segunda principal causa de morte no mundo, sendo considerado um problema de saúde pública que ganha contornos de ordem biopsicossociais, os quais necessitam da intervenção do assistente social. O presente estudo teve como objetivo retratar as subjetividades vivenciadas pelos pacientes oncológicos/hematológicos de um hospital de ensino na perspectiva do assistente social. Trata-se de uma pesquisa fundamentada na metodologia dialética, de abordagem qualitativa, exploratória e prospectiva, ocorrida no setor oncológico de um hospital de ensino, localizado no município de Campo Grande-MS, no período de maio a julho de 2016. A amostra contou com 10 voluntários, sendo utilizadas a entrevista semiestruturada e a análise de conteúdo para interpretação dos dados apurados. Dos depoimentos obtiveram-se as seguintes vertentes: fator cultural; atendimento psicológico; impossibilidade de trabalhar; colostomia nova realidade; determinantes do tratamento; atendimento do serviço social; tratamento quimioterápico. Conclui-se que a complexidade do atendimento integral das necessidades dos pacientes oncológicos requer que os mesmos sejam reconhecidos e compreendidos de forma multidimensional, por uma equipe multiprofissional, com abordagem interdisciplinar. Acredita-se que, por meio deste estudo, a transmissão dos anseios dos pacientes entrevistados do setor de oncologia tenha sido viabilizada, oportunizando a socialização de suas vivências, necessidades e carências.

Palavras-chave: Câncer. Hospital de Ensino. Serviço Social. Assistência à Saúde.

\begin{abstract}
Cancer is considered the second leading cause of death in the world, being considered a public health problem that has biopsychosocial contours, which require the intervention of the social worker. The present study aimed to portray the subjectivities experienced by oncological / hematological patients at a teaching hospital from the perspective of the social worker. This is a research based on the dialectical methodology of a qualitative, exploratory and prospective approach, which took place in the oncology sector of a teaching hospital located in the city of Campo Grande-MS from May to July 2016. The sample It had 10 volunteers, using a semi-structured interview and content analysis to interpret the data collected. From the statements the following aspects were obtained: cultural factor; psychological support; impossibility to work; colostomy new reality; determinants of treatment; social service attendance; chemotherapy treatment. It is concluded that the complexity of comprehensive care of the needs of cancer patients requires that they are recognized and understood in a multidimensional manner by a multidisciplinary team with an interdisciplinary approach. It is believed that, through this study, the transmission of the anxieties of the interviewed patients of the oncology sector was made possible, enabling the socialization of their experiences, their needs and needs.
\end{abstract}

Keywords: Cancer. Teaching Hospital. Social Service. Health Care.

\footnotetext{
1 Assistente Social Graduada pela Universidade Católica Dom Bosco. Especialista em Intensivismo pela Universidade Anhanguera - UNIDERP. Especialista em Psicologia Jurídica e Mediação de Conflitos pelo Centro Universitário Leonardo da Vinci. Especialista em Cuidados Continuados Integrados pela Universidade Federal de Mato Grosso do Sul/UFMS. Membro oficial do Comitê de Serviço Social da Academia Nacional de Cuidados Paliativos. https://orcid.org/0000-0001-6987-6383 E-mail: lansttai@gmail.com.

2 Assistente Social do Programa de Residência Multiprofissional em Cuidados Continuados Integrados da Universidade Federal de Mato Grosso do Sul/UFMS. Especialista em Gestão das Políticas Sociais pela Faculdade de Educação São Luis. https://orcid.org/0000-0002-9322-5465 E-mail: elifernanda.brandaolopes@gmail.com
} 


\section{Resumen}

El cáncer se identifica como la segunda causa principal de muerte en el mundo, siendo considerado un problema de salud pública que adquiere una naturaleza biopsicosocial, que requiere la intervención del trabajador social. El presente estudio tuvo como objetivo retratar las subjetividades experimentadas por pacientes con cáncer / hematológicos en un hospital universitario desde la perspectiva del trabajador social. Esta es una investigación basada en metodología dialéctica, con un enfoque cualitativo, exploratorio y prospectivo, que tuvo lugar en el sector de oncología de un hospital docente, ubicado en el municipio de Campo Grande-MS, de mayo a julio de 2016. La muestra incluyó con 10 voluntarios, utilizando entrevistas semiestructuradas y análisis de contenido para interpretar los datos obtenidos. De los testimonios se obtuvieron los siguientes aspectos: factor cultural; apoyo psicologico; incapacidad para trabajar; colostomía nueva realidad; determinantes del tratamiento; servicio de servicio social; tratamiento de quimioterapia. Se concluye que la complejidad de la atención integral para las necesidades de los pacientes con cáncer requiere que sean reconocidos y entendidos de manera multidimensional, por un equipo multidisciplinario, con un enfoque interdisciplinario. Se cree que, a través de este estudio, la transmisión de los deseos de los pacientes entrevistados del sector de oncología ha sido posible, brindando la oportunidad de socializar sus experiencias, necesidades y necesidades.

Palabras clave: Cáncer. Hospital de enseñanza. Servicio social. Asistencia de salud.

\section{INTRODUÇÃO}

O câncer é um problema de saúde pública de extensão mundial Segundo Souza, Cazola e Oliveira (2017), a estimativa da Organização Mundial da Saúde (OMS) para 2030 é de 27 milhões de novos casos de câncer e 75 milhões de pessoas vivendo com a doença no mundo. No Brasil, a estimativa para o biênio 2018-2019, elaborada pelo Instituto Nacional de Câncer (INCA), aponta para ocorrência de aproximadamente 600 mil casos novos de câncer em cada um desses anos, incluindo os casos de câncer de pele não melanoma (BRASIL, 2018a).

O câncer de próstata em homens e de mama em mulheres serão os mais frequentes na população, alcançando os números de 68 mil e 60 mil casos, respectivamente. Nos homens o câncer de próstata terá uma incidência de 31,7\%, seguido do câncer de pulmão, com 8,7\%; de intestino, com 8,1\%; de estômago, $6,3 \%$; e de cavidade oral, $5,2 \%$. Nas mulheres a incidência por câncer de mama será de 29,5\%; de intestino, 9,4\%; de colo do útero, 8,1\%; de pulmão, 6,2\%; e de tireoide, 4,0\% (SANTOS, 2018).

Em seus estudos, Nascimento, Rodrigues e Ferreira (2011, p. 642) apontaram que "apesar dos avanços tecnológicos na área do câncer", cerca de metade dos futuros pacientes com diagnóstico de algum tipo de câncer evoluirá para um "quadro situado fora da possibilidade de cura".

$\mathrm{Na}$ direção de prestar atendimento aos pacientes acometidos pelo câncer, a Lei no 12.732, de 22 de novembro de 2012, que dispõe sobre o primeiro tratamento do paciente comprovadamente acometido por neoplasia maligna e estabelece prazo para seu início, traz em seu art. $1^{\circ}$ o direito ao tratamento gratuito pelo Sistema Único de Saúde (SUS), assegurado 
ao paciente vítima de câncer. Em seu art. $2^{\circ}$, dispõe sobre o prazo de até 60 dias contados a partir do diagnóstico confirmado de câncer, para o início do primeiro tratamento disponibilizado pelo SUS (BRASIL, 2012).

A Portaria no 741, de 19 de dezembro de 2005, traz o Centro de Referência de Alta Complexidade em Oncologia como o serviço que "exerça o papel auxiliar, de caráter técnico, ao Gestor do SUS nas políticas de Atenção Oncológica" (BRASIL, 2005, p. 1) e tenha os seguintes atributos: ser Hospital de Ensino com certificado expedido pelo Ministério da Saúde e Ministério da Educação; ter atuação de base territorial; colaborar em nível local e regional, de forma articulada e integrada, com o sistema público de saúde; ter suporte e estrutura para desenvolver a pesquisa e o ensino de forma organizada; ter estrutura gerencial apropriada; subvencionar as ações dos gestores na regulação, fiscalização, controle e avaliação, incluindo estudos de qualidade e estudos de custo-efetividade; e, com base na Política Nacional de Educação Permanente em Saúde (PNEPS), atuar como polo de desenvolvimento profissional em parceria com o Gestor (BRASIL, 2015).

Os Hospitais de Ensino, de acordo com a Portaria Interministerial no 285, de 24 de março de 2015, são "estabelecimentos de saúde que pertencem ou são conveniados a uma Instituição de Ensino Superior (IES), pública ou privada, que sirvam de campo para a prática de atividades de ensino na área da saúde e que sejam certificados conforme o estabelecido nesta Portaria" (BRASIL, 2015, p. 1). A portaria supracitada possui como ementa a redefinição do Programa de Certificação de Hospitais de Ensino.

O Hospital de Ensino dever ter as condições estruturais mencionadas na Portaria no 3.410, de 30 de dezembro de 2013, que estabelece as diretrizes para a contratualização de hospitais no âmbito do SUS, em consonância com a Política Nacional de Atenção Hospitalar (BRASIL, 2013b), podendo contar como uma das linhas de cuidado, a oncologia adulta e pediátrica, sendo imprescindível que nela a atenção ao paciente seja realizada de forma interdisciplinar, levando em consideração a dimensão biopsicossocial. Faz-se necessária a intervenção do assistente social que avaliará os impactos dos determinantes sociais no processo saúde-doença, os quais podem interferir diretamente no tratamento do paciente.

Em sua pesquisa, Almeida et al. (2018, p. 78) assegura que a interação entre os aspectos "físicos, cognitivos, emocionais, sociais, culturais e espirituais" do paciente oncológico "demandam um olhar global sobre o mesmo, no qual oncologista, neurologista, assistente social, psicólogo, enfermeiro, terapeuta ocupacional e clérigo serão membros da equipe de assistência ao paciente com dor e sofrimento".

De acordo com Martinelli (2011, p. 503), a atuação do assistente social no contexto 
hospitalar "transcende os muros do hospital, buscando os núcleos de apoio na família, na comunidade, lugares sociais de pertencimento onde se dá o cotidiano de vida das pessoas", tendo o profissional um olhar para o indivíduo e não somente para a doença.

Além dos determinantes sociais da saúde que impactam diretamente no processo saúde-doença, observa-se que a parte estrutural da Unidade de Saúde também influencia na eficácia do tratamento do paciente. Segundo Mourão (2007), existem dificuldades a serem enfrentadas pelo profissional de Serviço Social:

A inserção dos assistentes sociais nos serviços de saúde, é importante pontuar, se dá na forma como a sociedade e seus empregadores recortam e compreendem as necessidades dos usuários, como organizam seus objetivos e que propostas de intervenção respondem as demandas e necessidades colocadas, pois o trabalho dos assistentes sociais não se realiza independente do contexto histórico, político e social que o determinam e o definem. Ao contrário, têm na conjuntura socioeconômica, política e institucional, suas possibilidades e limites (MOURÃO et al., 2007, p. 8).

A temática que envolve o paciente oncológico possui grande relevância para o entendimento do processo saúde/doença em todas suas facetas, considerando o indivíduo em sua dimensão biopsicossocial. De acordo com Siqueira, Barbosa e Boemer (2007, p. 2), “a experiência de adoecer com câncer é um fenômeno detentor de diferentes particularidades e que somente o Ser que vivencia esta situação é capaz de atribuir o significado de ser-comcâncer e revelar suas experiências [...]" Nesse sentido, chama-se a atenção para os aspectos subjetivos sociais, psicológicos, econômicos e culturais envolvidos no processo de saúdedoença e a necessidade do assistente social compor as equipes de atendimento ao paciente oncológico (GONZALEZ REY, 2010).

Assim sendo, torna-se necessário o estudo das subjetividades apresentadas pelos pacientes oncológicos, tendo em vista que as fragilidades e vulnerabilidade sociais inerentes à própria patologia refletem em demandas singulares apresentadas por esses pacientes, que necessitam de assistência diferenciada e especializada. A rede de atenção oncológica ainda demonstra fragilidades em relação à universalização do acesso, integralidade do cuidado e oferta de atendimento especializado e personalizado, apresentando barreiras sociais, culturais, institucionais, geográficas e econômicas que dificultam o acesso do paciente, em tempo oportuno, ao atendimento integral e contínuo, impactando na adesão ao tratamento e prognóstico da doença (TESTON et al., 2018).

A subjetividade do paciente oncológico é produzida em face do contexto social, a qual se encontra inserido, compondo-se de comportamentos, sentimentos, percepções, emoções, relações sociais etc. De acordo com Rezende e Ferreira Neto (2013, p. 41), a subjetividade do indivíduo manifesta-se de forma diferente em determinados contextos socioinstitucionais, 
apresentando-se em "relações de poder e de saber, provocando manifestações tanto de assujeitamento, de construção de autonomia".

Destarte, o paciente oncológico hospitalizado deve ser considerado em sua singularidade e particularidade. A equipe de saúde deve atuar de forma interdisciplinar, reconhecendo as subjetividades, fragilidades e potencialidades do paciente, levando em conta seus anseios, necessidades e temores, dessa forma suscitando questionamentos acerca das subjetividades vivenciadas por esses pacientes.

Nessa perspectiva, o presente estudo teve como objetivo retratar as subjetividades vivenciadas pelos pacientes oncológicos/hematológicos de um Hospital de Ensino, na perspectiva do assistente social.

\section{REFERENCIAL TEÓRICO}

Rezende e Ferreira Neto (2013) trazem que a subjetividade é formada tanto "por aspectos externos ao sujeito, como as questões institucionais e culturais, quanto por aspectos internos a ele, ou seja, as crenças e os valores de cada um". Destaca-se a importância do estudo das subjetividades vivenciadas por pacientes oncológicos, tendo em vista as fragilidades provocadas pela doença, que impactam negativamente em seu tratamento e se manifestam de maneira diferente em cada indivíduo.

A subjetividade do paciente oncológico, para Gonzalez Rey (2010), associa-se à sua capacidade de construir novas possibilidades frente à experiência do cotidiano do viver com câncer. Segundo o autor, a doença tem caráter objetivo e "não define as configurações subjetivas que, frente a sua emergência, são desenvolvidas pelo sujeito e que lhe permitem diversas formas de viver e sentir subjetivamente essa experiência" (GONZALEZ REY, 2010, p. 343).

Silva, Foger e Santos (2019) retratam o paciente oncológico hospitalizado como um ser fragilizado dentro do seu próprio "Eu", que o torna mais sensível, permitindo que ele perceba "como a equipe de saúde o está tratando, gerando mais angústias e conflitos diante do seu quadro" quando existe um relacionamento deficiente entre profissionais da saúde e indivíduos internados.

Nesse sentido, Munhoz et al. (2016, p.38) chamam a atenção da necessidade dos pacientes oncológicos serem acompanhados por "profissionais devidamente capacitados, sendo a condição mais ideal, a presença de uma equipe multidisciplinar", tendo em vista que as 
demandas apresentadas transcendem a questão da doença em si, perpassando pelas demais dimensões que compõem o processo saúde-doença.

De acordo com Landim e Carvalho (2015, p.9), o assistente social no contexto hospitalar não recebe somente demandas relacionadas à saúde, sendo este "referência no atendimento informativo a outras demandas, a exemplo das referentes à previdência social, a assistência social, dentre outras".

O adoecimento e a doença são experiências que vão além de alterações biológicas, fazendo parte de uma construção cultural, sendo a dor, nessa perspectiva, ligada culturalmente à gravidade da doença. Por isso, o câncer muitas vezes é diagnosticado tardiamente, pois suas primeiras manifestações não estão ligadas a um fenômeno doloroso, e suas alterações físicas não levam as pessoas a procurarem um atendimento de saúde, o fazendo apenas quando o processo de dor se intensifica (MUNIZ; ZAGO, 2009).

Os estudos de Oliveira, Cavalcante e Carvalho (2019) trazem os efeitos psicológicos das modificações corporais e de vida provadas pelo adoecimento oncológico, salientando que essas mudanças corporais acarretam em sofrimento, sendo o câncer ligado ao estigma negativo. Nesse contexto, inclui-se o emagrecimento, alopecia, colostomia e amputações.

Maruyama e Zago (2005) constataram, em uma pesquisa que buscou compreender como as pessoas com colostomia decorrente do câncer percebem o processo do adoecer, que ela é vista pelo paciente como uma interrupção de sua "vida comum", devido às mudanças ocorridas no corpo. Em razão do grande estigma do câncer, esses pacientes ficam sujeitos aos preconceitos. O adoecimento apresenta-se com diferentes significados baseados nas experiências dos pacientes com colostomia, partido das referências do seu contexto, da sua família e de suas atividades.

Segundo Wakiuchi et al. (2019), "o corpo é recinto de participação no mundo e na subjetividade", sendo assim, paciente oncológico, ao temer a exposição da doença, do ser pessoa vivendo com câncer, acaba por se limitar em suas relações. A quimioterapia é vista como a personificação da doença, uma vez que transfigura o corpo do paciente por meio dos seus efeitos colaterais.

O afastamento do trabalho devido à doença, associado à diminuição da renda e ao aumento dos gastos com alimentação e medicamento também são mudanças que impactam negativamente no tratamento oncológico. O trabalho também aparece como meio social de interação, parte da identidade do indivíduo; dessa forma, o afastamento do trabalho também gera angústias relacionadas à perda do papel social do paciente oncológico (WAKIUCHI et al., 2019). 
O câncer é uma doença multifacetada, que afeta diversas dimensões da vida do paciente. Sendo assim, os estudos de Lima, Melo e Silva (2015) trazem o assistente social como um profissional essencial no atendimento ao paciente em tratamento oncológico, considerando que ele atua diretamente nas mazelas advindas da questão social na qual se encontram inseridas as pessoas vivendo com câncer, promovendo a viabilização e ampliação dos direitos sociais.

Martinelli (2011), ao discutir o trabalho do assistente social no contexto hospitalar, traz o Serviço Social como sendo uma área de intervenção na realidade humana social, que necessita de grande mobilização por parte dos profissionais, para que a saúde seja fornecida de forma integral à população atendida, sendo uma atuação voltada "à consolidação dos direitos de cidadania dos usuários do hospital, de seus familiares e dos próprios trabalhadores da saúde" (MARTINELLI, 2011, p. 502).

Discutir as questões relativas ao paciente oncológico é discutir também as questões relativas ao acesso aos serviços de saúde, pois a diferenças nos intervalos entre o diagnóstico e tratamento do câncer estão relacionadas às "desigualdades na utilização dos serviços de alta complexidade em oncologia" (Cabral et al., 2019, p. 619)

Para Cabral et al. (2019, p. 619), o acesso aos serviços de saúde compõe-se de fatores "socioeconômicos, demográficos, culturais e psíquicos, necessidades de saúde, características dos serviços e dos profissionais, acesso geográfico e social disponíveis, entre outros", que impactam de modos diferentes na prevenção, cura ou reabilitação, nos serviços hospitalares e ambulatoriais.

\section{PROCEDIMENTOS METODOLÓGICOS}

Esta seção tem como finalidade descrever a metodologia utilizada no referido estudo, compondo-se de: Material e Métodos; Aspectos Éticos; e Construção e Análise de Dados.

Trata-se de uma pesquisa qualitativa, exploratória e prospectiva, utilizando-se dos procedimentos técnicos da pesquisa bibliográfica e do estudo de caso, fundamentando-se na metodologia dialética. Foi realizada com pacientes do setor de Oncologia adulto de um Hospital de Ensino, localizado no município de Campo Grande-MS, no período de maio a julho de 2016.

A dialética é a corrente filosófica do Marxismo, que norteia a intencionalidade do Serviço Social, tendo natureza qualitativa, pois "trabalha com o universo de significados, motivos, aspirações, crenças, valores e atitudes", demonstrando a preocupação com a compreensão da 
totalidade das relações, sendo que essa totalidade compreende as contradições que envolvem a produção dos fenômenos sociais (MINAYO, 2004, p.21-22).

Este método de abordagem penetra no mundo dos fenômenos e se propõe a abarcar o sistema de relações que se constrói nele, considerando a contradição inerente ao fenômeno. Analisa as representações sociais no mundo dos significados, situando a fala dos atores sociais dentro do contexto social para seu melhor compreendimento, sendo seus resultados uma aproximação da realidade social, que não pode ser reduzida a um mero dado de pesquisa (MINAYO, 2004)

O estudo de caso, segundo Becker (1993, p.118), possui dois desígnios, ao mesmo tempo em que busca a compreensão do grupo estudado, também tenta "desenvolver declarações teóricas mais gerais sobre regularidades do processo e estruturas sociais". O pesquisar ao se utilizar do estudo de caso em comunidade ou organização, também se dispõe do método da observação participante que possibilitará uma variedade de dados, inclusive dados não pensados no início da pesquisa, sendo ideal, portanto, aos objetivos do estudo de caso.

Os procedimentos técnicos da pesquisa bibliográfica consistem em pré-requisito para a realização de qualquer pesquisa. Para Lima e Mioto (2007, p. 44), a pesquisa bibliográfica pressupõe um conjunto ordenado de procedimentos de compreensão ao objeto de estudado, sendo capaz de gerar, "especialmente em temas pouco explorados, a postulação de hipóteses ou interpretações que servirão de ponto de partida para outras pesquisas".

Em termos éticos, a pesquisa foi realizada em conformidade com a Resolução ํo 466/2012 do Conselho Nacional de Saúde (CNS), que regulamenta a pesquisa envolvendo seres humanos. O Projeto foi submetido e aprovado pela Comissão de Diretoria de Ensino e Pesquisa e Organização Institucional (DPQI) e Plataforma Brasil, sob o número CAAE: 45216715.0.0000.5161.

Como fonte de coleta de dados, utilizou-se o sistema eletrônico de armazenamento de dados interno denominado SOULMV, versão: SMA-PEP 1.0.289-8, o prontuário dos pacientes atendidos participantes da pesquisa, e entrevistas semiestruturas com questões abertas e fechadas.

Foram incluídos na pesquisa, pacientes com idade entre 18 e 50 anos, residentes no estado do Mato Grosso do Sul, com diagnóstico de câncer confirmado a partir de janeiro de 2013, com pelo menos duas internações por conta da enfermidade no referido setor de oncologia (oncológicos ou hematológicos) do Hospital de Ensino mencionado e que aceitaram participar da pesquisa mediante assinatura do Termo de Consentimento Livre e Esclarecido 
(TCLE). Foram excluídos da pesquisa, os pacientes cuja evolução, no prontuário ou na ficha da enfermagem, constou comprometimento mental ou rebaixamento do nível de consciência.

O referido Hospital de Ensino possui a capacidade de 320 leitos, dos quais 30 são pertencentes ao Setor de Oncologia Adulto. A coleta dos dados foi realizada por um período de três meses, compreendendo maio, junho e julho de 2016, sendo a amostra constituída por 10 pacientes.

Para a definição da população desta pesquisa, utilizou-se como tipo de amostragem a amostra não probabilística do tipo intencional por critérios. Justifica-se o tamanho da amostra pela natureza da pesquisa qualitativa que busca a intensidade dos fenômenos, sendo geralmente realizada com amostra pequenas, pois "trabalha muito menos preocupada com os aspectos que se repetem e muito mais atenta com sua dimensão sociocultural que se expressa por meio de crenças, valores, opiniões, representações, formas de relação, simbologias, usos, costumes, comportamentos e práticas" (MINAYO, 2017).

A amostra não probabilística do tipo intencional por critérios configura-se, segundo Barbetta (2002), como sendo aquela em que os elementos selecionados da população para compor a amostra são escolhidos por critérios do pesquisador. De acordo com Fontanella et al. (2011, p. 388), definir o tamanho da amostra implica em estabelecer "o conjunto que subsidiará a análise e interpretação dos dados", sendo que "nas amostras não-probabilísticas (intencionais) tal definição é feita a partir da experiência do pesquisador no campo de pesquisa, numa empiria pautada em raciocínios instruídos por conhecimentos teóricos da relação entre o objeto de estudo e o corpus a ser estudado".

Depois de aplicados os critérios de inclusão e exclusão, os pacientes foram convidados a participar da pesquisa, mediante assinatura do TCLE (Termos de Consentimento Livre e Esclarecido), sendo realizadas entrevistas semiestruturadas, por meio de formulários elaborados e aplicados pela pesquisadora, contendo questões fechadas e abertas. As entrevistas foram gravadas e posteriormente transcritas.

Aos pacientes participantes do referido estudo, foram repassadas informações e esclarecimentos necessários sobre a pesquisa, demonstrando sua relevância. Garantiu-se o sigilo das informações coletadas, assim como o anonimato dos participantes. Os entrevistados foram identificados pela letra $E$, seguida pelo número da entrevista.

A forma utilizada para a análise e interpretação dos dados apurados no desenvolvimento da pesquisa foi a análise de discurso, que consiste em uma técnica que analisa a comunicação como tendo a função de compreender e refletir sobre os discursos que dos sujeitos fazem, para além do aparente. De acordo com Caregnato e Mutti (2006, p. 682), na análise de discurso 
"não é necessário analisar tudo que aparece na entrevista, pois se trata de uma análise vertical e não horizontal. O importante é captar a marca linguística e relacioná-la ao contexto sóciohistórico".

Assim, foram obtidos dos depoimentos as seguintes vertentes: fator cultural; atendimento psicológico; impossibilidade de trabalhar; colostomia nova realidade; determinantes do tratamento; atendimento do Serviço Social; tratamento quimioterápico.

Todos os pacientes participantes apresentaram características singulares, influenciadas por determinantes sociais da saúde, e que serão discutidas a seguir.

\section{RESULTADOS E DISCUSSÕES}

A Organização Mundial de Saúde (OMS) apresentou em 1948 um novo conceito para saúde, referindo-se a ela como o "estado de completo bem-estar físico, mental e social e não apenas a mera ausência de doença" (BEAGLEHOLE; BONITA; KJELLSTRON, 2007, p.15).

Em busca de avanços no conhecimento sobre o processo saúde-doença, em março de 2006 foi criada a Comissão Nacional sobre Determinantes Sociais da Saúde ${ }^{3}$, que definiu os DSS (Determinantes Sociais da Saúde) como sendo "fatores sociais, econômicos, culturais, étnicos/ raciais, psicológicos e comportamentais que influenciam a ocorrência de problemas de saúde e seus fatores de risco na população" (BUSS; FILHO, 2007, p. 78).

Igualmente, "o reconhecimento da questão social como objeto de intervenção profissional (conforme estabelecido nas Diretrizes Curriculares da ABEPSS, 1996) demanda atuação profissional em uma perspectiva totalizante [...]" (CFESS, 2010, p. 34-35), sendo o assistente social chamado a intervir sobre os DSS que permeiam o processo saúde-doença.

Sendo assim, a atuação do assistente social dentro da política de saúde deve considerar que as condições de vida e trabalho da população impactam diretamente na produção de saúde, tendo o adoecimento correlação com o processo de exploração e dependência econômica gerado pelo capitalismo, fatores esses que influenciam na dinâmica da vida dos sujeitos entrevistados.

\footnotetext{
${ }^{3}$ Conforme o documento do Conselho Federal de Serviço Social, intitulado os Parâmetros para a Atuação de Assistentes Sociais na Saúde, "A principal proposta da Reforma Sanitária é a defesa da universalização das políticas sociais e a garantia dos direitos sociais. Nessa direção, ressalta-se a concepção ampliada de saúde, considerada como melhores condições de vida e de trabalho, ou seja, com ênfase nos determinantes sociais; a nova organização do sistema de saúde por meio da construção do SUS, em consonância com os princípios da intersetorialidade, integralidade, descentralização, universalização, participação social e redefinição dos papéis institucionais das unidades políticas (União, Estado, municípios, territórios) na prestação dos serviços de saúde; e efetivo financiamento do Estado"(CFESS, 2010, p.19).
} 


\section{Perfil dos pacientes entrevistados}

Neste tópico será abordado o perfil dos pacientes entrevistados, descrevendo características relacionadas à idade, sexo, cor da pele, estado civil, escolaridade, renda, condições de moradia, localidade da moradia, pessoas com quem residem, diagnóstico e ano de diagnóstico.

- Branco, 37 anos, sexo masculino, com diagnóstico em dezembro de 2015 de leucemia linfoblástica aguda recidivada, ex-tabagista, vive em união estável, cursou ensino fundamental incompleto (3 ${ }^{\underline{a}}$ série), tatuador com registro em carteira, percebe benefício de Auxílio Doença. O paciente provém do município de Jardim/MS, onde reside com sua esposa e filho em casa própria de alvenaria, a qual conta com água encanada e corrente elétrica; (E1).

- Branca, 25 anos, sexo feminino, diagnóstico em fevereiro de 2016 de carcinoma de colo uterino invasor epidermóide - metástase renal, casada, genitora de três filhos, ensino fundamental completo, do lar (nunca laborou), com renda familiar proveniente do salário recebido pelo esposo. A paciente é oriunda de Campo Grande/MS, reside com o esposo e filhos em habitação cedida de tábua, a qual possui energia elétrica e poço artesiano; (E2).

- Branco, 45 anos, sexo masculino, com diagnóstico em 2014 de câncer de pâncreas com invasão gástrica, casado, possui um filho, ensino fundamental completo, cabeleireiro e produtor, com renda familiar proveniente do Benefício de Prestação Continuada-BPC. O paciente é oriundo do município de Campo Grande/MS, vive com cônjuge em habitação cedida de alvenaria, com água encanada e energia elétrica; (E3).

- Branca, 31 anos, sexo feminino, com diagnóstico em dezembro de 2015 de carcinoma espinocelular com recidiva local e inguinal, viúva, genitora de dois filhos, ensino superior incompleto (6º semestre do curso de Pedagogia), auxiliar de enfermagem com registro em carteira, renda familiar proveniente do Auxílio Doença. Paciente procedente de Campo Grande/MS, reside com seus genitores e filhos em imóvel cedido de alvenaria, com água encanada e energia elétrica; (E4).

- Branca, 50 anos, sexo feminino, com diagnóstico em 2013 de carcinoma de reto com metástase hepática, casada, possui um filho adotivo, ensino fundamental incompleto ( $5^{\mathrm{a}}$ série), doméstica com registro em carteira, em recebimento de 
Auxílio Doença. A paciente reside no munícipio de São Gabriel do Oeste/MS com esposo e filho, em imóvel próprio edificado em alvenaria, guarnecido com rede de água e energia; (E5).

- Branca, 47 anos, sexo feminino, com diagnóstico em dezembro de 2015 de câncer de intestino com suspeita de metástase, etilista, casada, genitora de duas filhas, ensino superior incompleto, comerciante, com renda proveniente de Auxílio Doença. Paciente moradora de Campo Grande/MS, reside com suas filhas em imóvel alugado de alvenaria, com rede de água e energia elétrica; (E6).

- Parda, 44 anos, sexo feminino, com diagnóstico em 2014 de cancro linfoma de Hodgkin, etilista, tabagista, viúva, genitora de dois filhos, alfabetizada, diarista com vínculo trabalhista, com renda originária do benefício Bolsa Família. Paciente procedente de Campo Grande/MS, reside sozinha em casa de alvenaria, com rede de água e energia elétrica (área de comodato); (E7).

- Branco, 26 anos, sexo masculino, com diagnóstico em 2016 de melanoma maligno cutâneo com recidiva, solteiro, ensino médio completo, técnico em manutenção e suporte de informática com registro em carteira, com renda proveniente de Auxílio Doença. Paciente do município de Campo Grande/MS, reside com sua irmã em habitação alugada de alvenaria, guarnecida com rede de água e energia; (E8).

- Pardo, 45 anos, sexo masculino, com diagnóstico em 2016 de carcinoma de reto com metástase hepática, ex-etilista, ex-tabagista, ex-dependente químico, casado legalmente (porém não vive com a esposa e ainda não deu entrada na separação judicial), genitor de dois filhos, ensino fundamental incompleto (5 $5^{\mathrm{a}}$ série), pedreiro, em recebimento de Auxílio Doença. Paciente morador de Campo Grande-MS, reside sozinho em imóvel próprio de alvenaria, com água encanada e energia elétrica; (E9).

- Parda, 30 anos, sexo feminino, com diagnóstico em junho de 2016 de neoplasia de transição retossigmóide com metástase hepática e carcinoma peritoneal, exetilista, solteira, genitora de três filhos, ensino fundamental completo, diarista sem registro em carteira de trabalho, com renda familiar proveniente do benefício Bolsa Família. Paciente munícipe de Campo Grande-MS, reside com esposo e filhos em imóvel próprio edificado em alvenaria, guarnecido com rede de água e energia elétrica; (E10). 
As características sociodemográficas dos pacientes entrevistados encontram-se descritas na Tabela 1.

\begin{tabular}{|c|c|c|}
\hline Dados Sociodemográficos & $\mathbf{N}$ & $\%$ \\
\hline \multicolumn{3}{|l|}{ Sexo } \\
\hline Feminino & 6 & $60 \%$ \\
\hline Masculino & 4 & $40 \%$ \\
\hline \multicolumn{3}{|l|}{ Estado Civil } \\
\hline Solteiro (a) & 2 & $20 \%$ \\
\hline Casado (a) & 5 & $50 \%$ \\
\hline Viúvo (a) & 2 & $20 \%$ \\
\hline Separado (a) & 0 & $0 \%$ \\
\hline União Estável & 1 & $10 \%$ \\
\hline \multicolumn{3}{|l|}{ Escolaridade } \\
\hline Alfabetizado (a) & 1 & $10 \%$ \\
\hline Ensino Fundamental Incompleto & 3 & $30 \%$ \\
\hline Ensino Fundamental Completo & 3 & $30 \%$ \\
\hline Ensino Médio Incompleto & 0 & $0 \%$ \\
\hline Ensino Médio Completo & 1 & $10 \%$ \\
\hline Ensino Superior Incompleto & 2 & $20 \%$ \\
\hline Ensino Superior Completo & 0 & $0 \%$ \\
\hline \multicolumn{3}{|l|}{ Domicílio } \\
\hline Campo Grande/MS & 8 & $80 \%$ \\
\hline São Gabriel do Oeste/MS & 1 & $10 \%$ \\
\hline Jardim/MS & 1 & $10 \%$ \\
\hline \multicolumn{3}{|l|}{ Renda } \\
\hline Suporte Familiar & 1 & $10 \%$ \\
\hline Auxílio-Doença & 6 & $60 \%$ \\
\hline Benefício de Prestação Continuada (BPC) & 1 & $10 \%$ \\
\hline Bolsa Família & 2 & $20 \%$ \\
\hline \multicolumn{3}{|l|}{ Ano do Diagnóstico } \\
\hline 2013 & 1 & $10 \%$ \\
\hline 2014 & 2 & $20 \%$ \\
\hline 2015 & 3 & $30 \%$ \\
\hline 2016 & 4 & $40 \%$ \\
\hline \multicolumn{3}{|l|}{ Condição de Moradia } \\
\hline Casa Própria & 4 & $40 \%$ \\
\hline Casa Alugada & 2 & $20 \%$ \\
\hline Casa Cedida & 3 & $30 \%$ \\
\hline Casa em Área de Comodato & 1 & $10 \%$ \\
\hline
\end{tabular}

Observa-se que a renda dos entrevistados provém de benefício previdenciário (Auxílio Doença $)^{4}$, benefício socioassistencial $(B P C)^{5}$ e programa de transferência de renda (Bolsa

\footnotetext{
${ }^{4}$ Segundo Simões, o Auxílio Doença "É o benefício pago ao segurado, quando este se torna incapaz para o trabalho, por doença ou acidente, desde que já tenha contribuído, na data da incapacidade, por pelo menos 12 meses (carência)" (SIMÕES, 2009, p.156).
} 
Família $)^{6}$, sendo a renda um fator que tem grande influência no tratamento do paciente oncológico.

No tocante à educação, percebe-se que a maioria dos entrevistados possui baixa escolaridade, sendo que nenhum paciente possui ensino superior completo, tendo apenas um dos entrevistados concluído o ensino médio completo. Em seus estudos, Carvalho (2008) traz dados do perfil dos pacientes atendidos no Instituto Nacional do Câncer (INCA) no Rio de Janeiro, que não diferem muito dos entrevistados nesta pesquisa:

Os usuários do Instituto Nacional de câncer (INCA) são, em sua maioria, provenientes das classes sociais menos favorecidas. Esta afirmativa se pauta no Registro Hospitalar de Câncer (RHC)/INCA 2000/2003, no qual se verifica que $62 \%$ dos pacientes (faixa etária acima de 15 anos) não alcançam sequer o primeiro grau completo (CARVALHO, 2008, p. 98).

Segundo Carvalho (2008), existe uma correlação entre o baixo nível de escolaridade e a vulnerabilidade socioeconômica. Os pacientes em situação de vulnerabilidade social sofrem um impacto muito maior com o câncer, "enfrentando dificuldades de acesso a bens e serviços para satisfação de necessidades básicas" (CARVALHO, 2008, p. 98).

Em uma pesquisa realizada por Cabral et. al (2019), que identificou os perfis sociodemográficos de mulheres com câncer de mama, constatou-se que as "desigualdades na utilização dos serviços de alta complexidade em oncologia", cujos fatores têm interação com as condições de vulnerabilidade do público estudado, impactam em piores resultados para a saúde. De acordo com o referido autor:

Desigualdades sociais - ou aquelas desigualdades que, quando associadas a características individuais como escolaridade, renda, etnia, entre outras, colocam alguns grupos em desvantagem em relação a outro - podem resultar não só em piores condições de saúde como também em desigualdades no acesso e utilização de serviços. O uso de serviços de saúde é um complexo resultante da interação de diversos fatores que abrangem características socioeconômicas, demográficas, culturais e psíquicas, necessidades de saúde, características dos serviços e dos profissionais, acesso geográfico e social disponíveis, entre outros (CABRAL et al., 2019, p. 619).

No Brasil, a ocorrência do câncer não tem distribuição homogênea entre as regiões do país, e aproximadamente $60 \%$ dos casos ocorrem em estados e municípios mais pobres, nas populações de baixa e média renda (BRASIL, 2018b).

\footnotetext{
${ }^{5}$ O Benefício de Prestação Continuada (BPC) é regulamentado pela Lei Orgânica da Assistência Social 꾸 8.742, de 7 de dezembro de 1993 (LOAS). Simões (2009) esclarece que "[...] têm direito de receber o BPC os brasileiros (inclusive naturalizados, com domicílio no país) com deficiência incapacitante ou idosos, que não tenham condições de prover sua própria subsistência ou por meio de sua família" (SIMÕES, 2009, p.327).

${ }^{6}$ O Programa Bolsa Família é preconizado pela Lei Ordinária no 10.836 , de 9 de janeiro de 2004, sendo um programa de transferência de renda (BRASIL, 2004, s/n).
} 


\section{SOBRE O TRATAMENTO: O ENFRENTAMENTO DA DOENÇA E O DESAFIO PARA VENCER UMA ENFERMIDADE COMPLEXA}

Esta seção tem como finalidade desenvolver as vertentes: fator cultural; atendimento psicológico; impossibilidade de trabalhar; colostomia nova realidade; determinantes do tratamento; atendimento do Serviço Social; e tratamento quimioterápico, que foram construídas mediantes a análise de discurso. Sendo possibilitado, por meio deste método de análise, o entendimento de aspectos mais subjetivos dos pacientes estudados.

\section{Fator cultural}

A perspectiva cultural trabalhada neste tópico tem referência nos autores Muniz e Zago (2009). Assinalam-se a seguir os depoimentos dos entrevistados quando indagados sobre a representação da doença para si:

Então foi recente né?! Fazendo o tratamento há três meses. Tô abalada psicologicamente... A gente nunca espera né?! Eu sempre tive uma alimentação muito saudável, nunca comi porcaria, fazia ginástica, caminhada e acontecer isso... Fiquei chocada! (E6)

No começo só pensava que ia morrer. Todo mundo fala você tem câncer você vai morrer, não tem cura, não tem cura... Agora que já me explicaram como é que tem tratamento tudo, eu já me conforto mais [...]. (E10)

Percebe-se dos discursos que a visão sobre a doença em si está estritamente ligada a pré-conceitos estabelecidos pela sociedade, construídos culturalmente, como estereótipo de estilo de vida saudável sendo sinônimo de uma dada imunidade a doenças, desconsiderando fatores genéticos e ambientais; e o estereótipo de câncer como doença incurável. Os estudos apontam o câncer como uma enfermidade multicausal crônica que "pode ter origem genética ou por fatores ambientais", porém hábitos de vida saudáveis ajudam na prevenção da doença (MUNHOZ et al., 2016, p. 34).

Muniz e Zago (2009, p. 28), em sua pesquisa sobre a construção sociocultural do câncer do ponto de vista das pessoas que vivem com a doença, demonstraram que ao considerar "a construção da experiência de ter câncer na perspectiva cultural", observa-se que "a trajetória dessas pessoas, desde a identificação dos primeiros sinais da doença, tem características subjetivas, que são identificadas e simbolizadas segundo o conhecimento prévio sobre a enfermidade", ou seja, "a teoria interpretativa da cultura representa a possibilidade de conhecer e compreender as várias maneiras como as pessoas constroem a vida e o processo de vivêla".

As representações culturais sobre a saúde e doença apresentam características diferentes dependendo do contexto social, econômico e religioso onde se encontra inserido o 
paciente, sendo que "o conhecimento do 'leigo', concernente à sua doença, difere da concepção dos profissionais de saúde" (SILVA; ZAGO, 2005, p. 477).

Em seus estudos, Cecilio et al. (2014, p. 1510) assinala que "o móbil do agir leigo são o adoecimento, a dor, o sofrimento e o sentimento de fragilidade inerentes à condição humana", sendo esse agir movido pelas necessidades de saúde em seu sentido mais amplo. Dentro do protagonismo do paciente tido como "leigo" existe uma infinidade de posicionamentos diante da doença, que vão desde a elaboração de explicações para adoecimento baseados no modelo biomédico, até explicações baseadas na subjetividade humana, podendo o paciente manifestar sentimentos de culpa pela doença.

De acordo com Wakiuchi et al. (2019, p. 138), o isolamento social do paciente provocado após o início da quimioterapia, em razão da queda do cabelo, evidencia o preconceito tanto da própria pessoa com câncer como da sociedade, onde o paciente, temendo a "atenção e os olhares que irá receber em locais públicos", passa a evitar as interações sociais, ficando segregado da sociedade.

Nesse sentido, chama-se a atenção para as questões subjetivas de representação da doença para o paciente oncológico, devendo a equipe de saúde que o assiste compreender a construção cultural da doença e os possíveis desdobramentos que ela gera sobre o tratamento e perspectiva de vida desse paciente.

\section{Atendimento psicológico}

No que se refere à questão de suporte psicológico, somente dois pacientes alegaram ter recebido atendimento psicológico, ficando os outros oito desassistidos pelo serviço de saúde.

O diagnóstico de câncer provoca no paciente ansiedade e angústia, de acordo com Silva e Zago (2005, p. 477): "revelar o diagnóstico do câncer é um momento crucial, e a forma como o profissional de saúde dá a notícia interfere diretamente na relação do paciente com o diagnóstico". Sendo assim, faz-se necessário que o profissional esteja preparado para o manejo correto dessa comunicação, sendo qualificado para comunicar más notícias.

Igualmente, a ciência do diagnóstico é necessária; nesse sentido, oito dos entrevistados afirmaram que costumam questionar sobre a evolução do seu quadro clínico, e todos alegam seguir corretamente os horários de medicamentos e as orientações médicas. Isso demonstra comprometimento e adesão ao seu projeto terapêutico, "quanto mais longo for o seguimento do tratamento", maior é "a necessidade de participação e adesão do sujeito no seu projeto 
terapêutico", assim como será maior "o desafio de lidar com o usuário enquanto sujeito, buscando sua participação e autonomia em seu projeto terapêutico" (BRASIL, 2009, p. 10).

Ressalta-se a necessidade de ser ofertado ao paciente o atendimento psicológico, devido à alta incidência do câncer e sua dimensão histórica como doença incurável, associada ao sofrimento e à morte, provocar um grande temor no paciente que recebe esse diagnóstico. Há, em razão disso, um desencadeamento de sentimentos de tristeza e angústia, podendo essas questões, se não tratadas, trazerem prejuízo à terapêutica proposta e à recuperação do paciente (SILVA, ZAGO, 2005; SILVA, FOGER, SANTOS, 2019).

\title{
Impossibilidade de trabalhar
}

No tocante às mudanças provocadas pela doença, pode ser percebido nos depoimentos dos entrevistados que a incapacidade laborativa ocupa um espaço significativo dentro das transformações ocorridas no cotidiano desses pacientes.

\begin{abstract}
Eu fazia tudo, cozinhava, lavava roupa e andava. Hoje eu não posso andar muito tempo. O máximo que eu aguento andar é pouco espaço assim né?! Sentar também não aguento que dói as costas. A maioria do tempo que eu aguento é só ficar deitada, deitada, deitada.... Chega a soar as costas e aí, no caso, vem a vontade de fazer as coisas de antes, não posso mais... Comida às vezes não quero comer, às vezes quero comer a minha comida né?! E aí eu tentei, lá na minha mãe, fazer a comida para mim, só que eu fiz na marra, por que eu achei que aguentava. Na minha cabeça eu aguentava fazer. Aí coloquei o tempero tudo, de repente, começou me dar fraqueza nas pernas. Aí eu tive que pegar o banco e sentar na cozinha e cozinhei sentada. Aí eu falei: desisti. Não vou mais mexer que eu tô vendo... Não sou aquela de antes. (E10)
\end{abstract}

O trabalho tem uma grande importância na vida do ser humano, fazendo parte da formação da subjetividade, identidade dos indivíduos e papel social exercido pelos mesmos, influenciando na construção da sociedade, associando-se a interesses econômicos, ideológicos e políticos (NEVES et al., 2018; WAKIUCHI et al.,2019).

A centralidade do trabalho, segundo Neves et al. (2018), "é entendida como o grau de importância que o trabalho tem na vida de uma pessoa, identificando o quanto é central para a autoimagem do sujeito". Dessa forma, o paciente que perde a capacidade laborativa perde também o papel social que desempenha perante a sociedade e perante sua família. As normas sociais sobre o trabalho se estabelecem como:

[...] modelos sociais que dizem respeito às recompensas obtidas pelo trabalho, gerando no trabalhador a percepção do que seriam trocas justas entre o que ele recebe do trabalho e as contribuições que ele traz. Finalmente, os resultados valorizados do trabalho são os valores relacionados aos motivos que levam uma pessoa a trabalhar, como, por exemplo, obter prestígio e retorno financeiro, manter-se em atividade, o contato social e estabelecimento de relações interpessoais, sentir-se útil para a sociedade, entre outros (NEVES et al., 2018, p. 321). 
Em seus estudos, Lima, Melo e Silva (2015, p. 68) salientam que "o afastamento do trabalho pode representar implicações sociais que impactam no processo de tratamento e na vida dos usuários", tendo em vista que, ao se afastar das suas atividades, o paciente segurado pela Previdência Social receberá o benefício de Auxílio Doença. Para Wakiuchi et al., (2019) "o afastamento do trabalho e o consequente impacto financeiro que se instala em decorrência disso" traz para o paciente oncológico uma nova realidade, levando-o à construção de "uma nova subjetividade".

O assistente social, no atendimento ao paciente oncológico, viabiliza o acesso ao benefício de Auxílio Doença, devendo o profissional orientar que a aquisição de tal benefício incorre em "perda na composição da renda familiar, pois o valor do benefício é de $91 \%$ da média dos salários de contribuição", não correspondendo, dessa forma, ao salário que era auferido pelo paciente antes do adoecimento (LIMA, MELO, SILVA, 2015 p. 68). Além disso, as vantagens, gratificações e horas extras não serão percebidas pelo paciente em curso de Auxílio Doença.

No Brasil, as pesquisas que mensuram o impacto do câncer ou incapacidades laborativas geradas pelo diagnóstico e tratamento são escassas, sendo o DALLY usado para medir os impactos da doença. Esse indicador mede "os anos de vida perdidos, seja por morte prematura (YLL -Years of Life Lost) ou incapacidade (YLD - Years Lived with Disability) em relação a uma esperança de vida ideal". O item YLD, como indicador de incapacidades secundárias ao câncer, mede apenas o tempo vivido com o diagnóstico sem, no entanto, avaliar o seu desfecho (LANDEIRO, 2017, p. 35).

Os impactos provocados pelo câncer na produtividade laboral são mensurados em "horas perdidas de trabalho, retorno ao trabalho, mudança no status de trabalho ou mesmo prejuízo nas atividades", o que acaba se mostrando um dificultador nas "comparações de diferentes populações ou efetividade de intervenções” (LANDEIRO, 2017, p. 36). Devem ser realizados estudos que mensurem os impactos da perda da capacidade laborativa nas dimensões sociais, econômicas, psicológicas e emocionais de pacientes oncológicos.

\section{Colostomia nova realidade}

Indagados como foi o período em que estiveram internados no referido Hospital de Ensino, os depoimentos assinalam que o período de internação foi positivo. Foram sinalizadas nos depoimentos as mudanças corporais provocadas pelo câncer, tendo um dos relatos 
apontado um problema relacionado à dificuldade em lidar com uma nova realidade: a colostomia.

Uma das terapias adotadas no caso de câncer colorretal é a colostomia, que consiste na ressecção cirúrgica do local afetado e na realização de uma ostomia permanente, que desviará o trajeto intestinal para uma abertura realizada na parede abdominal (MARUYAMA; ZAGO, 2005).

A colostomia é algo que requer uma orientação prévia para o paciente e/ou familiares, para o manuseio e aceitação desta necessidade. A seguir têm-se dois depoimentos referentes ao período de internação:

\begin{abstract}
[...] Não deram muita atenção na colostomia...Eu achei. Elas não queriam trocar a minha colostomia. Era obrigação da minha família. Enfermeiro ou técnico? Técnico de enfermagem, coisa que ninguém sabia, nem eu nem minha família, como lidar com isso. Mesmo assim, a gente já fez na sua frente e isso ficou meio chato para mim, para minha filha, a gente achou chato! (E6)
\end{abstract}

Para mim fui bem atendido! (E1)

Observa-se no primeiro depoimento o desconforto da paciente e de sua familiar em relação à colostomia, e o "mecanicismo" corriqueiro do profissional de saúde, que por lidar com estas questões diariamente, já as vê como algo natural, trabalhando sobre elas de maneira mecânica, não percebendo que para o paciente e seus familiares é algo novo, uma mudança que precisa de aceitação. O paciente e seus familiares devem ser acolhidos pela equipe de saúde e preparados para lidarem com as mudanças corporais ocasionadas pelo câncer.

Para Oliveira, Cavalcante e Carvalho (2019), essas mudanças corporais perpassam para além da perda física, repercutindo em uma perda de si, pois alteram a autoimagem, a autoestima e as interações sociais. A assimilação destas "modificações corporais possibilita a reconstrução da visão que o paciente tem de si, e este processo é facilitado pelo encontro intersubjetivo do paciente com os profissionais que cuidam singularmente dele" (OLIVEIRA; CAVALCANTE; CARVALHO, 2019, p. 1).

Em seus estudos, Maruyama e Zago (2005) afirmam que o câncer e a colostomia mudam permanentemente o cotidiano do paciente. O procedimento da colostomia é bem aceito entre os profissionais, porém para o paciente que irá passar por ele e se tornará uma pessoa vivendo com colostomia, representa um processo muito complexo, que constituirá "um dos momentos mais críticos da vida" desse paciente, por acarretar um "sistema complexo de análise e reflexão da própria biografia, cujos significados foram construídos ao longo das suas experiências de vida" (p. 217). 
O câncer e a colostomia têm forte impacto na vida do paciente, provocando estigmatização e sofrimento, causando mudanças no seu contexto familiar e nas atividades cotidianas. Maruyama e Zago (2005, p. 221) afirmam que os pacientes com colostomia "reagem distintamente à situação: conformando-se ou negando-se" sendo esta "uma experiência corporal, reflexiva, vivida entre o corpo, entre si mesmo e a sociedade, mediada pela cultura, um evento moldado culturalmente e, por isso, com múltiplos sentidos."

O paciente ostomizado passa por um processo experiencial, reflexivo e de ressignificação de conhecimento em relação ao próprio corpo. De acordo com Souza et al. (2011), nesse processo cada indivíduo:

[...] passa a entender que seu corpo comporta outras significações além do seu aspecto físico e biológico. Assim, no processo de adoecimento, a saúde e a doença estão diretamente ligadas ao contexto sociocultural de cada um, e se manifesta por meio de um corpo em tripla dimensão, ou seja: o corpo individual, o corpo social e o corpo político. Inicialmente é o corpo individual o que mais chama a atenção, pois neste a experiência de ostomizado temporário se relaciona ao próprio eu. Mas, o corpo social também passa a ser percebido e considerado, pois tem a ver com o corpo socialmente aceito e estimulado na sociedade em que vive, qual seja o corpo saudável do qual a presença da colostomia destoa. E, a percepção do corpo político tem por referência o trabalho, como um aspecto valorizado culturalmente (SOUZA et. al., 2011, p 59).

Para minimização das alterações, estigmas e sofrimento causados pela colostomia "no âmbito dos corpos individual, social e político", faz-se necessário que os profissionais de saúde realizem o acolhimento, passando as informações e orientações de forma clara ao paciente e familiar sobre o procedimento, sua necessidade e seu manuseio (SOUZA et al., 2011, p. 59).

\section{Determinantes do tratamento}

No que tange às dificuldades vivenciadas após a alta hospitalar, para continuidade no tratamento, sete dos pacientes declararam que não tiveram problemas para dar sequência à terapêutica proposta, e três apontaram algumas dificuldades, que se mostram como fatores determinantes no tratamento, podendo ser observados no seguinte depoimento:

Dificuldade para fazer o exame, biópsia que demorou quatro meses, foi um atraso. De um câncer poderia ter morrido né? Mas o Dr. F. K., quando eu cheguei aqui, ligou na hora para a $\mathrm{Dr}^{\mathrm{a}} \mathrm{C}$. Já me encaixaram para uma consulta na terça-feira mesmo, três dias depois. Quanto a isso eu não tenho que reclamar. É do laboratório realmente. Não sou só eu, várias pessoas eu vi isso, né?! Pelo SUS você pode morrer esperando resultado de exame. (E6)

Corroborando com o exposto no depoimento, Trufelli et al. (2008) explica que a demora de fechar um diagnóstico e iniciar o tratamento são fatores determinantes para o prognóstico do paciente; sendo assim, os atrasos e a demora diagnóstica e/ou terapêutica possibilitam o crescimento do tumor, prejudicando as chances de cura do paciente. 
É necessária a otimização do tempo na fase do diagnóstico da enfermidade para que se aumentem as chances da eficácia do tratamento dos pacientes.

No depoimento a seguir, a desnutrição calórica figura como um dos fatores determinantes do tratamento:

É engordar né?! Ganhar isso. Eu achei que ele ia falar que eu tinha que ganhar pelo menos dez, vinte quilos, mas ele falou que eu tenho que engordar pelo menos 5 quilos. Então está fácil. Basta agora eu ter força de vontade pra eu poder ganhar logo esse peso pra mim poder acabar com esse pesadelo! Eu coloco na minha cabeça que isso é um sonho que eu vou acordar e não passou de um sonho! Se Deus quiser. Coloca esse dreno aqui tudo pra dentro, que me incomoda também bastante, sentar e falar "nossa, que pesadelo esse sonho que eu tive". (E10)

No relato, a paciente expressa sua necessidade de ganho de peso, a qual está retardando a continuidade de sua terapêutica. Conforme o INCA (2013), a desnutrição está intrinsecamente ligada à enfermidade:

A desnutrição calórica e proteica em pacientes internados por diversas doenças, no Brasil, chega a quase $50,0 \%$, segundo dados do estudo multicêntrico Inquérito Brasileiro de Avaliação Nutricional (Ibranutri). Entre os pacientes com câncer, o índice chega a $66,4 \%$. Os principais fatores determinantes da desnutrição nos pacientes oncológicos são a redução na ingestão total de alimentos, as alterações metabólicas provocadas pelo tumor e o aumento da demanda calórica pelo crescimento do tumor. O estado nutricional do paciente é relevante para o sucesso do tratamento oncológico (INCA, 2013, p. 4).

Em consonância com as afirmações, "a intervenção nutricional adequada está associada à maior taxa de sobrevida, melhora do estado nutricional, da ingestão alimentar, da capacidade funcional e da qualidade de vida" (MUELLER et al., 2011, apud INCA, 2015a, p.41), devendo o paciente ser assistido pelo profissional nutricionista. Um bom estado nutricional mostra-se extremamente importante para evolução clínica do paciente oncológico, influenciando em melhor adaptação em programas de reabilitação, e na redução na taxa de reinternação (MILANI et al., 2018; MUNHOZ et al., 2016).

Nas entrevistas, constatou-se que seis dos pacientes haviam recebido orientações de como deveriam se alimentar, porém, somente quatro conseguiram seguir as orientações, verbalizando a dificuldade de se alimentarem por terem o paladar alterado pelas medicações. Nesse sentido, salienta-se a necessidade do atendimento em equipe multiprofissional composta por médicos, nutricionistas, farmacêuticos, fisioterapeutas, enfermeiros, psicólogos e assistentes sociais.

Outro depoimento traz como fator determinante do tratamento a seguinte dificuldade:

Tive porque meu filho tava assim, não tinha carro, não tinha um conforto para mi levar eu não tinha condições de andar, eu estava há dois meses acamada e minha perna ainda não estava aguentando ficar de pé [...] eu pesava $25 \mathrm{~kg}$. (E7)

Nesta fala, o fator determinante para realização do tratamento está relacionada com a questão do transporte, pois a paciente relata a dificuldade no deslocamento até o serviço de 
saúde, devido a não possuir meios próprios de transporte e apresentar um estado de saúde muito debilitado, dificultando o acesso ao transporte público.

Em uma pesquisa desenvolvida por Nugem, Santos e Oliveira (2012, p. 187), que avaliou o impacto que a mobilidade urbana acarreta sobre a saúde, constatou-se que a "relação transporte e saúde possui uma grande sinergia, pois, uma vez que se tenha uma viagem fatigante até o destino final do usuário de transporte, essa fadiga pode se transformar em vários problemas relacionados a saúde".

O transporte é utilizado por "variadas razões, tais como: ir para o trabalho, ir para a escola, agendar ou comparecer a consultas médicas em hospitais ou centros de saúde [...]", estando o transporte e a mobilidade relacionados a "políticas públicas de saúde que abordem o conceito ampliado de saúde, como um direito de todos e um dever do Estado" e não apenas à inexistência de doença (NUGEM; SANTOS; OLIVEIRA, 2012, p.186).

O transporte para proporcionar uma mobilidade saudável deve ser "seguro, confortável, pontual, digno, acessível, com uma estrutura coerente com a necessidade atual e futura", sendo considerado um determinante social da saúde (NUGEM; SANTOS; OLIVEIRA, 2012, p.187). Porém, estudos que fomentem a discussão acerca das questões de transporte e mobilidade dentro do contexto de paciente em tratamento oncológico são escassos na literatura.

\section{Atendimento do serviço social}

O atendimento realizado pelo profissional do Serviço Social no setor de oncologia do referido Hospital de Ensino ocorre via disparo (solicitação de atendimento realizado pelos profissionais de saúde), não sendo este o único setor sob a sua responsabilidade.

Indagados sobre a solicitação de atendimento pelo Serviço Social do hospital, seis dos entrevistados responderam que requisitaram o atendimento pelo profissional assistente social. Nesse sentido, é preciso dizer que, em um primeiro momento, o assistente social deve acolher o paciente e seus familiares. Santos (2006) esclarece a importância do acolhimento:

[...] um processo de intervenção profissional que incorpora as relações humanas. Não se limita ao ato de receber alguém, mas a uma sequência de atos dentre de um processo de trabalho. Envolve a escuta qualificada, com a valorização da demanda que procura o serviço oferecido, a identificação da situação problema, no âmbito individual, mas também coletivo (SANTOS, 2006, p. 58). 
A questão do vínculo familiar é muito complexa, principalmente para pacientes que não exerceram a paternagem ou maternagem ${ }^{7}$ e que, devido à patologia, encontram-se fragilizados não só fisicamente como materialmente, necessitando de assistência por parte de sua família, que pode abster-se quando não existe vínculo afetivo intrafamiliar.

Outrossim, há pacientes que não constituíram família, e há os que as têm e possuem grande vínculo afetivo, porém, apesar de possuírem vínculos afetivos fortalecido, algumas dessas famílias se encontram em situação de vulnerabilidade social, e, portanto, não têm condições necessárias para acolher o paciente, seja por dificuldades "financeiras, emocionais e/ou organizacionais" (ANDRADE, 2009, p. 221).

Essas situações de fragilidades são expressões da questão social, a qual é o objeto de intervenção do profissional de Serviço Social. Neste caso, é imprescindível a atuação do assistente social na reorganização da dinâmica familiar, no estímulo às competências e potencialidades da família para superação das adversidades. Segundo Almeida et al. (2016), o assistente social no trabalho com as famílias, ao intervir em seus territórios de abrangência, deve "identificar e potencializar as habilidades e potencialidades ali existentes, alicerçados por um compromisso mútuo entre profissionais".

Quanto ao aspecto da avaliação socioeconômica, algumas informações são imprescindíveis para o atendimento do assistente social: "composição familiar, local de moradia, renda, religião, formação, profissão e situação empregatícia do paciente" (ANDRADE, 2009, p. 221).

No tocante às questões relacionadas aos direitos do paciente oncológico, somente quatro dos entrevistados responderam que conhecem seus direitos enquanto pessoa vivendo com câncer. Nesse sentido, o Serviço Social do referido Hospital de Ensino vem formulando ações almejando socializar informações quanto a bens e serviços em geral, melhorando a qualidade da assistência prestada, esclarecendo os direitos dos pacientes oncológicos.

Isso corrobora para o entendimento dos direitos por parte dos pacientes, o que justifica a necessidade das orientações realizadas pelo assistente social no âmbito hospitalar, referentes às políticas de previdência social e assistência social. Ressalta-se o entender do Instituto Nacional do Câncer - INCA (2015b):

Considerando que o trabalho informal, sem regime de proteção social, é uma realidade ainda muito presente na sociedade brasileira, os trabalhadores são privados dos direitos trabalhistas e sociais, em função do sistema de proteção social que, na política de previdência social, reconhece o direito somente aos filiados ao Regime Geral da

\footnotetext{
7 Tanto a paternagem quanto a maternagem implicam em cuidados físicos e afetivos oferecidos aos filhos, também denominados nurturance, palavra da língua inglesa que designa o ato de nutrir e que inclui o significado de relação duradoura baseada na cooperação, afeição e amor (COLLIER; ROSALDO; YANAGISAKO, 1992 apud ABADE, 2014 p. 20).
} 
Previdência Social, não absorvendo uma grande parte da população brasileira em idade produtiva, que não está inserida no mercado formal de trabalho ou que não dispõe de condições financeiras para contribuições facultativas. A Política de Assistência Social utiliza-se do critério seletivo a quem dela necessitar, e somente a Política de Saúde possui a universalização do acesso sem contribuições prévias e diretas (INCA, 2015b, p. 77).

Porém, quando questionados se existe a necessidade de orientação do assistente social ou do atendimento para auxiliar em alguma questão não resolvida referente à parte social, somente dois informaram que sim. Nesse caso, acredita-se que esse resultado é o reflexo da falta de conhecimento de todas as atribuições do assistente social por parte de alguns entrevistados.

Em um estudo realizado por Landim e Carvalho (2015), que analisou o cotidiano profissional dos assistentes sociais em um hospital, revelou-se que a procura pelo assistente social se dá principalmente, por questões culturais, em que o profissional é associado ao "faz de tudo", devido ao desconhecimento do usuário das atribuições desse profissional.

Outrossim, o assistente social é também um profissional da saúde. Na perspectiva de esclarecer sua atuação nessa política, um documento foi elaborado pelo Conselho Federal de Serviço Social (CFESS) em 2010. Denominado "Parâmetros para a Atuação de Assistentes Sociais na Saúde", esse documento explicita a atuação do profissional em quatro eixos: "atendimento direto aos usuários; mobilização, participação e controle social; investigação, planejamento e gestão; assessoria, qualificação e formação profissional" (CFESS, 2010, p. 41).

Uma análise realizada através do "Relatório de Atendimento do Serviço Social" revelou que o Serviço Social do hospital de ensino em questão, esclarecendo as atribuições do profissional e reconhecendo o usuário como sujeito de direitos, em 2015, realizou 2.120 procedimentos junto aos pacientes do setor oncológico, demonstrando a grande necessidade de atendimento desse segmento (RELATÓRIO, 2015).

O Serviço Social tem atuação direta no campo das políticas sociais, compreendendo neste o da política de saúde, viabilizando o acesso aos direitos garantidos ao paciente oncológico, orientando "suas ações no compromisso de fortalecer o cuidado integral ao usuário", percebendo a saúde como "resultante das condições de alimentação, habitação, educação, renda, meio ambiente, trabalho, transporte, lazer etc." (INCA, 2019, p. 6).

De acordo com Lima, Melo e Silva (2015), em um estudo que retratou a discussão sobre o papel fundamental da proteção social no contexto de adoecimento do paciente oncológico, existe um conjunto significativo de direitos estendidos ao paciente acometido por câncer: Auxílio Doença ou licença médica; aposentadoria por invalidez; Benefício de Prestação Continuada (BPC); isenção do Imposto de Renda (IR) na aposentadoria, do Imposto sobre Produtos Industrializados (IPI), do Imposto de Circulação de Mercadorias e sobre Prestação de 
Serviços (ICMS), do Imposto de Propriedade de Veículos Automotores (IPVA) e do Imposto Predial e Territorial Urbano (IPTU); saques do Fundo de Garantia do Tempo de Serviço (FGTS), do Programa de Integração Social (PIS) e do Programa de Formação do Patrimônio do Servidor Público (PASEP), passe para uso de transporte coletivo, e Tratamento Fora do Domicílio (TFD).

Além desses direitos, a cartilha "Direitos sociais da pessoa com câncer: Orientações aos usuários" produzida em 2019 pelo INCA no Rio de Janeiro, também menciona: o direito à Licença para Tratamento de Saúde e a Licença por Motivo de Doença em Pessoa da Família, concedidas aos servidores públicos acometidos por câncer ou por familiar diagnosticado com a doença; a isenção do Imposto sobre Operações Financeiras (IOF); acréscimo de $25 \%$ sobre a aposentadoria por invalidez; quitação de financiamento de imóvel pelo Sistema Financeiro de Habitação (SFH) em caso de invalidez ou morte, prioridade na tramitação de processos; sepultamento gratuito estendido às famílias que não possuem condições financeiras para custear as despesas com funeral; atendimento gratuito pelo SUS ao paciente estrangeiro com câncer e testamento vital (INCA, 2019). Percebe-se, diante do exposto, a necessidade da atuação do assistente social no contexto hospitalar, para viabilização dos direitos sociais dos pacientes vivendo com câncer.

\section{Tratamento quimioterápico}

Os efeitos adversos da quimioterapia podem ser divididos em dois grupos: agudos, que se iniciam minutos após a administração dos agentes antineoplásicos e persistem por alguns dias, e tardios, que aparecem semanas ou meses após a infusão dos mesmos. A maioria das drogas induz à depressão da medula óssea em graus variáveis, dependendo do agente e da dose utilizada, bem como de fatores intrínsecos. São frequentes também a alopecia e as alterações gastrointestinais. Mesmo quando chega com sucesso ao fim do tratamento, ainda é necessário que o paciente conviva com o medo da recidiva e com as sequelas que sobrevêm de um tratamento oncológico (MANSANO-SCHLOSSER; CEOLIM, 2012, p, 601).

Quando indagados sobre o que poderia ser mudado no setor de oncologia do hospital, e o que melhoraria o tempo de permanência nele, seis entrevistados afirmam não ter nada a ser realizado. Quatro sinalizam questões relacionadas à dinâmica hospitalar para a realização do tratamento quimioterápico:

Por que né?! É ruim ficar nessa cadeira! Depende de tanto de dia que você vai ficar. A gente não né? A gente tá aqui. Tá sendo bem tratado. E os acompanhantes? (E2) 
Eu gostaria que tivesse só duas camas. Eu acho apertado. (E6)

Mais rápido as coisas da quimioterapia, às vezes chega gente de longe.... Eu chego, eu sou de longe, de São Gabriel! [...] (E5)

Acho assim, o que eu constatei ontem mesmo que poderia melhorar, tipo assim, eu, semana passada na consulta, ela falou assim "bom, você vai internar". Aí a gente chega aqui para internar e fiquei mais de duas horas para subir para a internação. Já atrasa o meu tratamento! Assim como minha aplicação do meu remédio. Aí marcou duas horas, subi já quase quatro horas, quatro e meia. Subi. Aí chega aqui o remédio tem dia que vem chegar só dez horas, onze horas e então começar aplicar. Então isso aí poderia melhorar! Você está agendado desde a consulta, tal dia duas horas você interna, aí eles me atrasam minha internação?! Onde você ficou duas horas pra conseguir internar? Na recepção é isso? Na recepção! Mais de duas horas... E eles alegaram o quê? Eu cheguei duas, fui internado quatro e meia, subi quatro e meia! A demora então para conseguir subir para o andar? Se já tem o dia que vem internar, por que não sobe logo? A gente fica lá dormindo nas cadeiras. Fora essa demora desse subir que já tá uma coisa agendada certa! (E3)

Segundo os "Protocolos Clínicos e Diretrizes Terapêuticas em Oncologia", elaborados pelo Ministério da Saúde (BRASIL, 2014, p. 52), deve ser realizada a "verificação dos percentuais das frequências dos procedimentos quimioterápicos em suas diferentes linhas (cuja ordem decrescente - primeira linha maior do que a segunda, maior do que terceira sinaliza a efetividade terapêutica)", para mensuração da efetividade do tratamento.

A existência e a observância das condutas e protocolo adotados nos hospitais devem ser executadas por meio de ações de auditoria in loco, verificando:

[...] regulação do acesso assistencial; qualidade da autorização; a conformidade da prescrição e da dispensação e administração dos medicamentos (tipos e doses); compatibilidade do procedimento codificado com o diagnóstico e capacidade funcional (escala de Zubrod); a compatibilidade da cobrança com os serviços executados; a abrangência e a integralidade assistenciais; e o grau de satisfação dos doentes (BRASIL, 2014, p. 52).

Observa-se que mesmo com os protocolos existentes ainda há necessidade de aperfeiçoar o atendimento aos pacientes que realizam tratamento quimioterápico no Hospital de Ensino, lócus da referida pesquisa, conforme segue o relato:

Você tem mais alguma coisa que você possa falar? Eu acho que a quimio também poderia chegar no horário, mas tem dia que vem chegar é onze horas da noite pra começar. Eles falam de chega cinco horas. Nunca aplica cinco horas. É erro da farmácia mesmo. Eu acho. Chega onze horas para colocar aqui para você, é isso que você está falando? Tem dia que eles vêm colocar onze horas da noite. Não sei se chega ali, onze horas. Quanto tempo leva para você fazer uma bolsa dessa? Tem uma que é vinte e duas horas. Eu tomo duas de vinte e duas. Aí explica para mim: tá programado para a quimio, por exemplo, a quimio ser mais cedo. Pra você, tem que ter um horário certo para estar ministrando ela, é isso? Explica para mim. Não adianta né?! Se eu vou ficar 24 horas aqui no caso, começo onze horas a primeira vou terminar onze horas dali da noite do outro frasco né?! (E3)

Neste depoimento, o paciente relata a demora para realização da quimioterapia e seu termino em horários inoportunos, que dificultam o regresso do paciente ao seu domicílio. Para que a quimioterapia seja realizada é necessário que o paciente seja internado, e que esta 
internação seja confirmada pelo hospital, tendo em vista que o medicamento a ser ministrado somente será preparado após essa confirmação, pois a quantidade e dose específica são produzidas sob medida para cada paciente.

Outro fator importante a ser considerado é que as pessoas acometidas pela doença precisam sentir-se seguras com os procedimentos realizados, o que contribui para a confiança no tratamento e, consequentemente, repercute na sua autoestima e autoconfiança.

Em seus estudos, Cruz e Rossato (2015, p.339) ressaltam "a necessidade de capacitações e educação continuada permanentes" para todos os profissionais de saúde, "desde os que atuam em unidades hospitalares exclusivamente oncológicas, até os que atuam em ESF", devendo essa formação permitir a compreensão dos fatores biopsicossociais relacionados ao adoecimento causado pelo câncer nas suas múltiplas dimensões.

Cruz e Rossato (2015, p.339) sugerem "a criação de um plano de educação continuada permanente, por meio de parcerias entre a Coordenadoria Regional de Saúde (CRS), a rede hospitalar pela Residência Multiprofissional em Saúde (RMS) em Atenção ao Câncer e os Municípios que compõem a CRS", para que haja maior capacitação de profissionais da saúde que prestam assistência ao paciente oncológico.

Nesse sentido, justifica-se a necessidade do aumento no número de Programas de Residência Multiprofissional em Oncologia, devendo a atuação dos residentes ocorrer "em redes hospitalares e da atenção básica", atingindo "um maior nível de conhecimento" que garanta ao pacientes oncológicos uma atenção integral e humanizada conforme preconizado pela "Portaria do Ministério da Saúde $n^{\circ} 874$ de 16 de maio de 2013, que institui a Política Nacional para a Prevenção e Controle do Câncer na Rede de Atenção à Saúde das Pessoas com Doenças Crônicas no âmbito do SUS" (CRUZ; ROSSATO, 2015, p. 340).

Ressalta-se a importância dos relatos dos pacientes entrevistados na referida pesquisa sob a perspectiva do assistente social, no sentido de observá-los para aprimorar o processo e a assistência prestada, pois, dessa forma, as políticas públicas em relação ao direito a saúde da pessoa vivendo com câncer poderão ser elaboradas e executadas com maior qualidade, fortalecendo o direito à dignidade da pessoa humana.

\section{CONSIDERAÇÕES FINAIS}

A complexidade para o atendimento integral das necessidades do paciente oncológico requer a compreensão multidimensional do ser humano e uma atenção interdisciplinar através de uma equipe multiprofissional. Neste contexto, evidencia-se a necessidade de qualificação 
de profissionais para o atendimento deste público em específico, por meio de Programas de Residência Multiprofissional em Oncologia.

É imprescindível que haja o fortalecimento dos vínculos entre o paciente e seus familiares. Em alguns casos, também se faz indispensável a capacitação do cuidador, para a realização da assistência à saúde do paciente em ambiente domiciliar. Os vínculos familiares devem ser trabalhados pela equipe de saúde, capacitando e auxiliando a família e o paciente a lidar com as questões vindas dessa nova realidade. Ressalta-se a importância do assistente social no fortalecimento dos vínculos familiares, para reinserção social e comunitária do paciente oncológico.

A atuação da equipe multiprofissional soma-se muito neste processo, sendo necessário que a elaboração do projeto terapêutico singular atenda o paciente integralmente, reduzindo, dessa forma, o número de internações desnecessárias e gastos ao SUS. Salienta-se a necessidade de oferta de serviços especializados e personalizados na rede de atenção oncológica, levando em consideração a singularidade que permeia o paciente oncológico.

Esse paciente deve ser visto para além da doença, em uma visão holística do ser social e das suas relações sociais, não se tratando de negar a questão biológica, onde se manifesta a doença, mas sim perceber que a doença em si não é unicausal, sendo esta determinada socialmente, devendo ser consideradas as questões sociais, culturais, emocionais, psicológicas e econômicas que permeiam o processo do adoecimento do paciente oncológico,

Chama-se atenção para as mudanças corporais provocadas pelo câncer que impactam na autoestima e na autoimagem do paciente, podendo influenciar negativamente no tratamento, devendo ser ele assistido em suas questões psicológicas e emocionais por profissionais capacitados para lidar com os aspectos subjetivos da doença. O câncer apresenta-se como uma doença totalmente estigmatizada na sociedade, podendo levar o paciente a situações de preconceito e segregação social.

Salienta-se que as questões relacionadas à renda, trabalho e emprego têm implicações diretas no tratamento oncológico do paciente, devendo ser consideradas e analisadas durante este processo. Neste caso, faz-se necessária a atuação do assistente social para que sejam viabilizados os direitos assegurados em lei, no que tange à pessoa vivendo com câncer, auxiliando o paciente e seus familiares na adaptação à internação e ao tratamento da doença, na superação das vulnerabilidades sociais, identificando as potencialidades e fragilidades da rede de apoio social.

Percebeu-se, através do estudo das subjetividades dos pacientes oncológicos, que as fragilidades e vulnerabilidade sociais apresentadas e vinculadas à própria patologia se 
apresentam em demandas singulares, relacionadas às questões social e psicológica, aspectos nutricionais, cuidados relacionados à colostomia e quimioterapia, necessitando de assistência diferenciada e especializada de vários profissionais.

Já no que tange à quimioterapia, seria indicado que a internação do paciente fosse realizada no período matutino, para que assim que ele chegasse ao hospital fosse feita a confirmação do procedimento e o preparo da medicação a ser ministrado, tendo como resultado disso a liberação dos mesmos em horários mais adequados, levando em conta sua fragilidade tanto física quanto social.

Por fim, salienta-se a necessidade de novos estudos sobre a temática, tendo em vista a importância de se analisar a subjetividade do paciente oncológico, suas fragilidades e necessidades, para promover a ampliação das políticas públicas de atendimento, e reorganização dos serviços prestados na rede de atenção oncológica.

Acredita-se que, por meio deste estudo, conseguiu-se transmitir um pouco dos anseios dos pacientes entrevistados do setor de oncologia do hospital de ensino, que participaram de forma voluntária, oportunizando, assim, socializar um pouco de sua vivência, suas necessidades e carências, sob a perspectiva do assistente social.

\section{REFERÊNCIAS}

ABADE, Flavia. Famílias patrifocais: paternagem e socialização dos filhos. 2014. Dissertação (Mestrado em Psicologia) - Faculdade de Filosofia, Ciências e Letras de Ribeirão Preto, Universidade de São Paulo, Ribeirão Preto, 2014.

ALMEIDA, Leiliane Chaves Mageste. et. al. Principais Situações de Vulnerabilidade Social das Famílias da Microrregião de Ubá, MG. Oikos: Revista Brasileira de Economia Doméstica, Viçosa, v. 27, n.1, p. 31-58, 2016.

ALMEIDA, Vitoria Cordovil. et. al. A singularidade da dor de pacientes oncológicos em cuidados paliativos. Mudanças-Psicologia da Saúde, v. 26, n. 1, p. 75-83, jan-jun. 2018.

ANDRADE, Letícia. Papel do Assistente Social na equipe de cuidados paliativos. In: Manual de cuidados paliativos da ANCP, Rio de Janeiro: Diagraphic, p. 221-223, 2009.

BARBETTA, Pedro Alberto. Estatística aplicada às Ciências Sociais. 5. ed. Florianópolis: Ed. da UFSC, 2002.

BEAGLEHOLE, Robert; BONITA, Ruth; KJELLSTRON, Tord. Epidemiologia Básica. 2. ed. São Paulo: Santos, 2007.

BECKER, Howard. Métodos de Pesquisa em Ciências Sociais. São Paulo: Huciter, 1993. 
BRASIL. Lei no 10.836, de 9 de janeiro de 2004. Cria o Programa Bolsa Família e dá outras providências. Disponível em: http://www.planalto.gov.br/ccivil 03/ Ato2004-

2006/2004/Lei/L10.836.htm. Acesso em: 01 dez. 2019

BRASIL. Lei $\mathbf{n}$ - 12.732, de 22 de novembro de 2012. Dispõe sobre o primeiro tratamento de paciente com neoplasia maligna comprovada e estabelece prazo para seu início. Disponível em: http://www.planalto.gov.br/ccivil 03/ ato2011-2014/2012/lei/l12732.htm. Acesso em: 01 dez. 2019

BRASIL. Ministério da Saúde. Instituto Nacional de Câncer José Alencar Gomes da Silva.

Estimativas 2018. Rio de Janeiro: INCA, 2018a. Disponível em:

http://www1.inca.gov.br/estimativa/2018/. Acesso em: 17 nov. 2019

BRASIL. Ministério da Saúde. Secretaria de Atenção à Saúde. Política Nacional de Humanização da Atenção e Gestão do SUS. Clínica ampliada e compartilhada. Brasília: Ministério da Saúde, 2009.

BRASIL. Ministério da Saúde. Secretaria de Atenção à Saúde. Protocolos clínicos e diretrizes terapêuticas em Oncologia. Brasília: Ministério da Saúde, 2014

BRASIL. Ministério da Saúde. Secretaria de Vigilância em Saúde. Departamento de Vigilância em Saúde Ambiental e Saúde do Trabalhador. Atlas do Câncer Relacionado ao Trabalho no Brasil. Brasília: Ministério da Saúde, 2018b.

BRASIL. Portaria Interministerial no 285, de 24 de março de 2015. Redefine o Programa de Certificação de Hospitais de Ensino (HE). Disponível em:

http://bvsms.saude.gov.br/bvs/saudelegis/gm/2015/prt0285 2403 2015.html. Acesso em: 01 dez. 2019

BRASIL. Portaria n $\mathbf{3 . 4 1 0}$, de 30 de dezembro de 2013b. Estabelece as diretrizes para a contratualização de hospitais no âmbito do Sistema Único de Saúde (SUS) em consonância com a Política Nacional de Atenção Hospitalar (PNHOSP). Disponível em:

http://bvsms.saude.gov.br/bvs/saudelegis/gm/2014/prt3410 3012 2013.html. Acesso em: 01 dez. 2019

BRASIL. Secretaria Nacional de Assistência à Saúde. Portaria no 741 de 19 de dezembro de 2005. Disponível em:

http://bvsms.saude.gov.br/bvs/saudelegis/sas/2005/prt0741 1912 2005.html. Acesso em: 12 nov.2019.

BUSS, Paulo Marchiori; FILHO, Alberto Pellegrini Filho. A Saúde e seus Determinantes Sociais. Physis: Revista de Saúde Coletiva,v. 17, n. 1, p. 77-93, 2007.

CABRAL, Ana Lucia Viana. et al. Vulnerabilidade social e câncer de mama: diferenciais no intervalo entre o diagnóstico e o tratamento em mulheres de diferentes perfis sociodemográficos. Ciênc. saúde coletiva, Rio de Janeiro, v. 24, n. 2, p. 613-622, 2019.

CAREGNATO, Rita Catalina Aquino; MUTTI, Regina. Pesquisa qualitativa: análise de discurso versus análise de conteúdo. Texto contexto - enferm., Florianópolis , v. 15, n. 4, p. 679-684, 2006. 
CARVALHO, Célia da silva Ulysses. A necessária atenção à família do paciente oncológico.

Ver Bras Cancerol, v. 54, n. 1, p. 97-102, 2008.

CECILIO, Luiz Carlos de Oliveira. et. al. O agir leigo e o cuidado em saúde: a produção de mapas de cuidado. Cadernos de Saúde Pública [online], v. 30, n. 7, p. 1502-1514, 2014.

CFESS. Conselho Federal de Serviço Social. Parâmetros para a Atuação de Assistentes Sociais na Saúde. Brasília: CFESS, 2010.

CRUZ, Fernanda Strapazzon; ROSSATO, Luciana Grazziotin. Cuidados com o paciente oncológico em tratamento quimioterápico: o conhecimento dos enfermeiros da Estratégia Saúde da Família. Rev. Bras. Cancerol. [Internet], v. 61, n. 4, p. 335-341, 2015.

FONTANELLA, Bruno Jose Barcellos et al. Amostragem em pesquisas qualitativas: proposta de procedimentos para constatar saturação teórica. Cad. Saúde Pública, Rio de Janeiro, v. 27, n. 2, p. 388-394, 2011.

GONZALEZ REY, Fernanda Luis. As configurações subjetivas do câncer: um estudo de casos em uma perspectiva construtivo-interpretativa. Psicol. cienc. prof., Brasília, v. 30, n. 2, p. 328345, 2010.

INCA. Instituto Nacional de Câncer José Alencar Gomes da Silva. Cadernos de Psicologia: Os tempos no hospital oncológico. Rio de Janeiro: INCA, 2015b.

INCA. Instituto Nacional de Câncer José Alencar Gomes da Silva. Coordenação de Assistência. Direitos sociais da pessoa com câncer. 5. ed., Rio de Janeiro: Inca, 2019.

INCA. Instituto Nacional de Câncer José Alencar Gomes da Silva. Coordenação Geral de Gestão Assistencial. Hospital do Câncer I. Serviço de Nutrição e Dietética. Consenso nacional de nutrição oncológica organização. 2. ed. rev. ampl., Rio de Janeiro: INCA, 2015a.

INCA. Instituto Nacional de Câncer José Alencar Gomes da Silva. Inquérito brasileiro de nutrição oncológica. Rio de Janeiro: INCA, 2013.

LANDEIRO, Luciana Castro Garcia. Retorno ao trabalho em pacientes com câncer de mama tratadas em um serviço oncológico do Sistema Único de Saúde (SUS). Tese (Doutorado em Oncologia) - Faculdade de Medicina, Universidade de São Paulo, São Paulo, 2017.

LANDIM, Eveline de Sousa; CARVALHO, Jéssica Araújo. O cotidiano profissional dos assistentes sociais no Hospital Nossa Senhora da Conceição. In: I Congresso Internacional de Política Social e Serviço Social: Desafios Contemporâneos. Londrina-PR, jun. 2015.

LIMA, Priscila Ribeiro; MELO, Fernanda dos Reis; SILVA, Letícia Batista. Proteção social versus adoecimento por carcinoma epidermóide: Contribuições do serviço social. Serviço Social e Saúde, v. 13, n. 1, p. 61-76, 2015.

LIMA, Telma Cristiane Sasso; MIOTO, Regina Célia Tamaso. Procedimentos metodológicos na construção do conhecimento científico: a pesquisa bibliográfica. Rev. katálysis, Florianópolis, v. 10, n. spe, p. 37-45, 2007. 
MANSANO-SCHLOSSER, Thalyta Cristina; CEOLIM, Maria Filomena. Quality Of Life Of Cancer Patients During The Chemotherapy Period. Texto contexto - enferm., Florianópolis , v. 21, n. 3, p. 600-607, 2012.

MARTINELLI, Maria Lúcia. O trabalho do assistente social em contextos hospitalares: desafios cotidianos. Serv. Soc. Soc., São Paulo, n. 107, p. 497-508, set. 2011.

MARUYAMA, Sônia Ayako Tao; ZAGO, Márcia Maria Fontão. O processo de adoecer do portador de colostomia por câncer. Rev. Latino-Am. Enfermagem, Ribeirão Preto, v. 13, n. 2, p. 216-222, 2005.

MILANI, Juliana. et al. Anthropometry versus subjective nutritional assessment in cancer patients. Acta paul. enferm., São Paulo , v. 31, n. 3, p. 240-246, 2018

MINAYO, Maria Cecília de Souza. Amostragem e saturação em pesquisa qualitativa: consensos e controvérsias. Revista Pesquisa Qualitativa. São Paulo, v.5, n.7, p.01-12, abril 2017.

MINAYO, Maria Cecília de Souza. Pesquisa Social: Teoria, método e criatividade. Petrópolis, RJ: Vozes, 2004.

MOURÃO, Ana Maria Arreguy. et al.A Formação dos Trabalhadores Sociais no Contexto Neoliberal. O projeto das residências em Saúde da Faculdade de Serviço Social da Universidade Federal de Juiz de Fora. In: MOTA, Ana Elizabete et al. (Org.). Serviço Social e Saúde: formação e trabalho profissional. 2. Ed. São Paulo: Cortez, 2007.

MUNHOZ, Mariane Pravato et al. Efeito do exercício físico e da nutrição na prevenção do câncer. Revista Odontológica de Araçatuba, v. 37, n. 2, p. 09-16, 2016.

MUNIZ, Rosani Manfrin; ZAGO, Márcia Maria Fontão. A perspectiva cultural no cuidado de enfermagem ao paciente oncológico. Rev Cienc Cuid Saude[Internet], v. 8, n. 3, p. 23-30, 2009.

NASCIMENTO, Marília Beserra de Andrade; RODRIGUES, Juliana Stoppa Menezes; FERREIRA, Noeli Marchioro Liston Andrade. Quando a cura não é mais possível: escutando familiares de doentes com câncer. Ciência Cuidado e Saúde, v.10, n. 4, p. 642-649, 2011.

NEVES, Diana Rebello et. al. Meaning and Significance of work: a review of articles published in journals associated with the Scientific Periodicals Electronic Library. Cad. EBAPE.BR, Rio de Janeiro, v. 16, n. 2, p. 318-330, 2018.

NUGEM, Rita de Cássia; SANTOS, Carlos Honorato Schuch; OLIVEIRA, Celmar Corrêa. Transporte coletivo e saúde: uma questão de gestão. Revista da Universidade Vale do Rio Verde, Três Corações, v. 10, n. 1, p. 186-198, 2012.

OLIVEIRA, Dhiene Santana Araújo; CAVALCANTE, Luciana Suelly Barros; CARVALHO, Ricardo Tavares. Feelings of Patients in Palliative Care about Corporal Modifications Caused by Cancer. Psicol. cienc. prof., Brasília, v. 39, e176879, 2019. 
RELATÓRIO. Relatório de atendimento do Serviço Social. Setor de Oncologia. Hospital Regional do Mato Grosso do Sul. Campo Grande/MS. 2015. Não Publicado.

REZENDE, Maria Carolina Costa; FERREIRA NETO, João Leite. Subjectivity processes of a team of oncology nursing. Rev. Psicol. Saúde, Campo Grande, v. 5, n. 1, p. 40-48, 2013.

SANTOS, Eva Teresinha. O acolhimento como um processo de intervenção do serviço Social junto a mulheres em situação de violência. 2006. Monografia (Curso de Serviço Social) -

Universidade Federal de Santa Catarina, Departamento de Serviço Social, Florianópolis, 2006.

SANTOS, Marceli de Oliveira. Estimativa 2018: Incidência de Câncer no Brasil. Rev. Bras.

Cancerol. v. 64, n. 1, p. 119-120, 2018.

SILVA, Tamires; FOGER, Debora; SANTOS, Paulo. Depersonalization of hospitalized patients: an integrative review. Psic., Saúde \& Doenças, Lisboa, v. 20, n. 3, p. 651-658, 2019.

SILVA, Valéria Costa Evangelista; ZAGO, Márcia Maria Fontão. A revelação do diagnóstico de câncer para profissionais e pacientes. Revista Brasileira de Enfermagem, v. 58, n. 4, p. 476480, 2005.

SIMÕES, Carlos. Curso de direito do serviço social.3 ed. rev., São Paulo: Cortez, 2009.

SIQUEIRA, Karina Machado; BARBOSA, Maria Alves; BOEMER, Magali Roseira. O vivenciar a situação de ser com câncer: alguns des-velamentos. Revista Latino-Americana de Enfermagem, v. 15, n.4, p. 605-611, 2007.

SOUZA, Geize Rocha Macedo; CAZOLA, Luiza Helena de Oliveira; OLIVEIRA, Sandra Maria do Valle Leone. Atuação dos enfermeiros da estratégia saúde da família na atenção oncológica. Esc. Anna Nery, Rio de Janeiro, v. 21, n. 4, e20160380, 2017.

SOUZA, Pollyane Chris Menino. et. al. As repercussões de viver com uma colostomia temporária nos corpos: individual, social e político. Rev. Eletr. Enf. [Internet], v.13, n. 1, p. 5059, 2011.

TESTON, Elen Ferraz. et al. Feelings and difficulties experienced by cancer patients along the diagnostic and therapeutic itineraries. Esc. Anna Nery, Rio de Janeiro, v. 22, n. 4, 2018.

TRUFELLI, Damila Cristina. et al. Análise do atraso no diagnóstico e tratamento do câncer de mama em um hospital público. Revista da Associação Médica Brasileira, v. 54, n. 1, p. $72-$ 76, 2008.

WAKIUCHI, Julia. et al. Rebuilding subjectivity from the experience of cancer and its treatment. Rev. Bras. Enferm., Brasília, v. 72, n. 1, p. 125-133, 2019. 